\title{
Characterization and Role of SCAI during Renal Fibrosis and Epithelial-to-Mesenchymal Transition
}

\author{
Attila Fintha, ${ }^{*}$ Ákos Gasparics, ${ }^{\dagger}$ Lilla Fang, ${ }^{\dagger}$ Zsuzsa Erdei, $^{\ddagger}$ Péter Hamar, ${ }^{\dagger}$ Miklós M. Mózes, $^{\dagger}$ Gábor Kökény, $^{\dagger}$ \\ László Rosivall, ${ }^{\dagger \S}$ and Attila Sebe ${ }^{\dagger}$
}

From the $2^{\text {nd }}$ Department of Pathology* and the Department of Pathophysiology, ${ }^{\dagger}$ Semmelweis University, Budapest; and the Membrane Research Group ${ }^{\ddagger}$ and the Research Group for Pediatrics and Nephrology, ${ }^{\S}$ Hungarian Academy of Sciences and Semmelweis University, Budapest, Hungary

\author{
Accepted for publication \\ October 16, 2012. \\ Address correspondence to \\ Attila Sebe, M.D., Ph.D., \\ Department of Pathophysi- \\ ology, Semmelweis University, \\ Nagyvárad Square 4, Floor 18, \\ Room 1810, 1089 Budapest, \\ Hungary. E-mail: sebe.attila@ \\ med.semmelweis-univ.hu.
}

\begin{abstract}
During progressive tubulointerstitial fibrosis, renal tubular epithelial cells transform into $\alpha$-smooth muscle actin (SMA)-expressing myofibroblasts via epithelial-to-mesenchymal transition (EMT). SMA expression is regulated by transforming growth factor (TGF)- $\beta 1$ and cell contact disruption, through signaling events targeting the serum response factor-myocardin-related transcription factor (MRTF) complex. MRTFs are important regulators of fibrosis, tumor cell invasion, and metastasis. Consistent with the role of MRTFs in tumor progression, suppressor of cancer cell invasion (SCAI) was recently identified as a negative regulator of MRTF. Herein, we studied the role of SCAI in a fibrotic EMT model established on LLC-PK1 cells. SCAI overexpression prevented SMA promoter activation induced by TGF- $\beta 1$. When co-expressed, it inhibited the stimulatory effects of MRTF-A, MRTF-B or the constitutive active forms of RhoA, Rac1, or Cdc42 on the SMA promoter. SCAI interfered with TGF- $\beta 1$-induced SMA, connective tissue growth factor, and calponin protein expression; it rescued TGF- $\beta 1$-induced E-cadherin down-regulation. IHC studies on human kidneys showed that SCAI expression is reduced during fibrosis. Kidneys of diabetic rats and mice with unilateral ureteral obstruction depicted significant loss of SCAI expression. In parallel with the decrease of SCAI protein expression, diabetic rat and mouse kidneys with unilateral ureteral obstruction showed SMA expression, as evidenced by using Western blot analysis. Finally, TGF- $\beta 1$ treatment of LLC-PK1 cells attenuated SCAI protein expression. These data suggest that SCAI is a novel transcriptional cofactor that regulates EMT and renal fibrosis. (Am J Pathol 2013, 182: 388-400; http://dx.doi.org/10.1016/j.ajpath.2012.10.009)
\end{abstract}

Progressive tubulointerstitial fibrosis (TIF) is a common manifestation for a variety of chronic kidney diseases, leading to end-stage renal failure. The histopathological characteristics of TIF are deposition of extracellular matrix, tubular cell loss, and a robust accumulation of fibroblasts. These fibroblasts may have different cellular origins: proliferation of resident fibroblasts, tubular epithelial or endothelial cells may convert after epithelial-to-mesenchymal transition (EMT) or endothelial-mesenchymal transition, bone marrow-derived fibrocytes, and pericytes. ${ }^{1}$ EMT plays a key role in organ development and during several pathological conditions, such as cancer progression and fibrosis. At the cellular level, EMT is regulated by similar signaling pathways, regulators, and effector molecules, both under physiological and pathological conditions. ${ }^{2}$

The unequivocal importance of EMT during TIF was described in a transgenic mouse model of TIF, in which nearly $40 \%$ of fibroblasts originated from the tubular epithelium that underwent EMT. ${ }^{3}$ Several fibrogenic stimuli induce epithelial cell transformation to myofibroblasts, yet the most potent regulator of renal EMT is transforming growth factor (TGF)- $\beta 1 .^{4}$ During renal EMT, tubular cells lose their epithelial markers (eg, E-cadherin and zonula occludens protein-1), express fibroblast-specific and mesenchymal proteins (eg, fibroblast-specific protein 1 and plasminogen activator inhibitor-1), start to synthesize extracellular matrix (eg, fibronectin), and ultimately differentiate into $\alpha$-smooth muscle actin (SMA)-positive cells, showing a myofibroblast-like phenotype. They follow a sequentially orchestrated, defined chronology: down-regulation of the epithelial program, activation of the mesenchymal-fibrogenic program, and, finally, activation of the myogenic program.

Supported by the Hungarian Kidney Foundation. 
Myofibroblasts arise after a completed EMT, a sequence of events eventually culminating in the appearance of myogenic characteristics. ${ }^{5,6}$

De novo expression of SMA in cells that undergo EMT is a hallmark of myofibroblast formation. Regulation of SMA expression is highly complex, and it involves several signaling steps. TGF- $\beta 1$ and cell-cell contact-dependent signaling, after an injury of intercellular contacts, are both necessary to induce SMA expression. ${ }^{7,8}$ Activation of the small GTPases RhoA, Rac1, and Cdc42 and their downstream effectors (Rho kinase and P21-activated kinase) and other downstream signaling steps, including myosin light chain and p38 phosphorylation, ${ }^{8-12}$ regulate SMA expression. These signals converge toward serum response factor (SRF), which coordinates gene expression by binding to CArG boxes present in the promoters of several genes. ${ }^{13-16}$ Myocardin-related transcription factors (MRTFs) emerged as key mediators of SMA expression, ${ }^{8,17}$ by binding and activating SRF and regulating SRF functions as SRF transcriptional cofactors. ${ }^{18-21}$ Nuclear translocation and accumulation of MRTF was induced by TGF- $\beta 1$, RhoA, Rac1, and Cdc42 small GTPases, ${ }^{8,10,12,22}$ whereas MRTF inhibition prevented SMA expression. ${ }^{8,16}$

MRTFs have an important role during development of the cardiovascular system, ${ }^{23}$ skeletal myogenic differentiation, ${ }^{24}$ and brain development. ${ }^{25}$ MRTFs are also involved in several pathological processes. In addition to their role in fibrosis, MRTFs are important regulators of tumor cell invasion and metastasis. ${ }^{26}$

Consistent with the role of MRTFs in tumor progression, suppressor of cancer cell invasion (SCAI) was recently identified as an inhibitor of MRTF, which is downregulated in various tumors. ${ }^{27}$ Mainly localized in nuclei, SCAI is a cofactor of MRTF, rendering an inhibitory effect on MRTF-SRF-dependent protein expression. It antagonizes the up-regulation of $\beta_{1}$-integrin expression, leading to an inhibition of tumor cell invasiveness. Recent data suggest that MRTF contributes to dendritic complexity of rat cortical neurons, and overexpression of SCAI blocks SRF-dependent transcriptional responses and dendritic complexity. ${ }^{28}$

Because SCAI is also expressed in the kidneys, we proposed to investigate its potential protective role in a model of fibrotic EMT and in the regulation of SMA expression. For this study, we used our previously described EMT model established in LLC-PK1 cells. SCAI overexpression prevented SMA promoter activation induced by TGF- $\beta 1$. When co-expressed with MRTF-A and MRTF-B, or the constitutive active forms of RhoA, Rac1, or Cdc42, it inhibited the stimulatory effect of these signaling molecules on the SMA promoter. SCAI prevented TGF- $\beta 1$-induced E-cadherin down-regulation and interfered with TGF- $\beta 1$-induced SMA, connective tissue growth factor (CTGF), and calponin protein expression. In concordance with findings in different tumors, SCAI mRNA and protein expression was down-regulated in fibrotic kidney samples, compared with nonfibrotic kidneys.
In vivo studies revealed a significant decline in SCAI protein expression in an early phase of diabetic nephropathy and in a mouse unilateral ureteral obstruction (UUO) model. In parallel with the decrease of SCAI protein expression, diabetic rat and UUO mouse kidneys showed SMA expression, as evidenced by using Western blot analysis. Finally, TGF- $\beta 1$ treatment led to the attenuation of SCAI protein and mRNA expression in vitro. These data suggest that SCAI may serve as a potential diagnostic, prognostic, and therapeutic target in fibrotic diseases, renal fibrosis, and EMT.

\section{Materials and Methods}

\section{Cell Culture and Treatments}

LLC-PK1 (CL4) proximal tubular epithelial cells and mIMCD-3 inner medullary collecting duct cells were cultured in Dulbecco's modified Eagle's medium (Invitrogen, Carlsbad, CA), supplemented with $10 \%$ fetal bovine serum (Invitrogen) and $1 \%$ penicillin-streptomycin at $37^{\circ} \mathrm{C}$ under a humidified atmosphere containing $5 \% \mathrm{CO}_{2}$. Cells were grown on 6- or 24-well plates, and then subjected to various treatments. For chronic $\mathrm{Ca}^{2+}$ deprivation, cells were washed three times with PBS (Invitrogen) and incubated in low $\mathrm{Ca}^{2+}$-containing Dulbecco's modified Eagle's medium (Invitrogen). Control samples were incubated with serumfree Dulbecco's modified Eagle's medium containing $\mathrm{Ca}^{2+}$. TGF- $\beta 1$ (Sigma-Aldrich, St. Louis, MO) treatments were performed as specified at the individual experiments $(10 \mathrm{ng} / \mathrm{mL}$ or vehicle for controls).

\section{Plasmids}

The PA3-Luc vector containing a 765-bp fragment of the rat SMA promoter (pSMA-Luc) was a kind gift from Dr. Raphael Nemenoff (University of Colorado, Denver, $\mathrm{CO})$. The p152-SMA-Luc reporter construct, containing a 152-bp portion of the rat SMA promoter in a pGL3-basic vector, was provided by Sem H. Phan (University of Michigan Medical School, Ann Arbor, MI). The thymidine kinase-driven Renilla luciferase vector (pRL-TK), used as an internal control for transfection efficiency, was obtained from Promega (Madison, WI).

Green fluorescent protein (GFP)-tagged wild-type SCAI and GFP-tagged construct containing the N-terminally truncated version of SCAI (GFP-SCAI and GFP-SCAI $\Delta$ nt) were obtained from Dr. Robert Grosse (University of Heidelberg, Heidelberg, Germany) and were previously described. ${ }^{27}$ FLAG-tagged MRTF-A and MRTF-B were kindly provided by Dr. Eric N. Olson (University of Texas, Dallas, TX) and were previously described. ${ }^{18}$ The vector encoding for Myc-tagged constitutive active RhoA (Q63L, CA-Rho) was described and used in our previous studies. ${ }^{8}$ GFP-tagged constitutively active Rac1 (Q61L, CA-Rac1) and constitutively active Cdc42 (Q61L, CA-Cdc42) were 
obtained from Dr. Gary M. Bokoch (The Scripps Research Institute, La Jolla, CA) and were previously described. ${ }^{29}$

\section{Transient Transfection and Luciferase Promoter Activity Assays}

Cells were grown on 6-well plates and transfected using $2.5 \mu \mathrm{L}$ of FuGene6 (Roche, Mannheim, Germany) reagent/1 $\mu \mathrm{g}$ DNA. For promoter activity measurements, cells were cotransfected with $0.5 \mu \mathrm{g}$ of promoter construct, $0.05 \mu \mathrm{g}$ of pRL-TK, and $2 \mu \mathrm{g}$ of either empty vector (pcDNA3.1) or the specific construct to be tested. After a 24-hour incubation period, cells were washed and placed in a serum-free medium, either containing or lacking $\mathrm{Ca}^{2+}$. TGF- $\beta 1(10 \mathrm{ng} / \mathrm{mL})$ or its vehicle was added to the cells after 4 hours, and the incubation was continued for an additional 16 hours. Firefly and Renilla luciferase activities were measured by the Dual-Luciferase Reporter Assay Kit (Promega) using a Victor X3 2030 Multilabel Plate Reader (PerkinElmer, Waltham, MA), according to the manufacturer's instructions. Cells were passively lysed in passive lysis buffer, following the instructions of the manufacturer (Promega). Results were normalized by dividing the Firefly luciferase activity by the Renilla luciferase activity of the same sample. For each condition, duplicate measurements were performed, and experiments were repeated at least three times. Results are presented as mean \pm SE. For immunofluorescence analysis, typically 1 to $2 \mu \mathrm{g}$ of plasmid DNA was transfected per well.

\section{LLC-PK1 Cells Stably Expressing GFP-SCAI}

Cells were transfected with $1 \mu \mathrm{g}$ of GFP-SCAI plasmid and $3 \mu \mathrm{L}$ of FuGene6 (Roche) reagent. Three days after transfection, cells were sorted based on GFP fluorescence using the fluorescence-activated cell sorting Aria High Speed Cell Sorter (Becton-Dickinson, San Jose, CA). Sorted GFPpositive cells were expanded and were subjected to repeated sorting, 4 and 8 weeks after transfection. The cells obtained after three sorting cycles were almost completely GFP-SCAI positive, stably GFP-SCAI-expressing LLCPK1 cells, as evidenced by flow cytometry. For flow cytometry, GFP-SCAI-transfected LLC-PK1 cells were analyzed based on GFP fluorescence. Propidium iodide staining was used to gate out the nonviable cells. Samples were analyzed by an FACSCalibur flow cytometer with CellQuest acquisition software (both from Becton Dickinson Immunocytometry Systems, San Jose, CA).

\section{Antibodies}

Anti- $\alpha$-SMA, anti- $\beta$-actin, anti-SCAI [used for immunohistochemical (IHC) studies of rat kidney samples and Western blot analysis], and anti- $\alpha$-tubulin antibodies were obtained from Sigma. Anti-E-cadherin, anti-calponin, and peroxidaseconjugated anti-goat antibodies were obtained from Dako
(Glostrup, Denmark). Anti-CTGF antibody was from Santa Cruz Biotechnology (Santa Cruz, CA). Anti-glyceraldehyde3-phosphate dehydrogenase (GAPDH) was from Millipore (Billerica, MA). Alexa 594-labeled anti-mouse and Alexa 568-labeled anti-rat antibodies were obtained from Invitrogen. The rat monoclonal SCAI antibody (used in immunofluorescence and human IHC studies) was obtained from Dr. Robert Grosse and was previously described. ${ }^{27}$ UUO kidney samples were also probed for SCAI expression by Western blot analysis using an anti-SCAI antibody obtained from Abcam (Cambridge, MA). Peroxidase-conjugated antimouse and anti-rabbit secondary antibodies were obtained from Jackson Immunoresearch Laboratories Inc. (West Grove, PA) and Cell Signaling (Danvers, MA).

\section{Western Blot Analysis}

Cells were scraped into Triton lysis buffer $[30 \mathrm{mmol} / \mathrm{L}$ HEPES (pH 7.4), $100 \mathrm{mmol} / \mathrm{L} \mathrm{NaCl}, 1 \mathrm{mmol} / \mathrm{L}$ EGTA, $20 \mathrm{mmol} / \mathrm{L} \mathrm{NaF}, 1 \%$ Triton X-100, $1 \mathrm{mmol} / \mathrm{L} \mathrm{Na}_{3} \mathrm{VO}_{4}$, $1 \mathrm{mmol} / \mathrm{L}$ phenylmethylsulphonyl fluoride, and $20 \mu \mathrm{L} / \mathrm{mL}$ protease inhibitory cocktail (Pharmingen, San Diego, CA)]. Protein concentration was determined using the BCA Protein Assay (Pierce Thermo Scientific, Rockford, IL). Samples were mixed in a 1:1 ratio with two times Laemmli buffer and boiled for 5 minutes. Equal amounts of protein were separated on $12 \%$ SDS-polyacrylamide gel and transferred to nitrocellulose membranes. Membranes were blocked with Trisbuffered saline, containing $0.1 \%$ Tween 20 and 5\% skim milk for an hour, and then incubated overnight with the primary antibody (in Tris-buffered saline-Tween 20 plus $0.5 \%$ skim milk), extensively washed, and incubated with the corresponding peroxidase-conjugated secondary antibody. Blots were visualized by the electrochemiluminescence detection system (Thermo Scientific, Waltham, MA). Quantification results are presented as mean $\pm \mathrm{SE}$.

For Western blot analysis of rat kidney samples, four control and four diabetic kidneys were dissociated into cortex and medulla. Medullas were then homogenized into $200 \mu \mathrm{L}$ of radioimmunoprecipitation assay (RIPA) buffer using a tissue glass Dounce homogenizer (Sigma). Protein concentration was determined by the BCA Protein Assay. Samples were diluted into RIPA buffer, and $20 \mu \mathrm{g}$ was loaded for Western blot analysis.

For Western blot analysis of UUO mouse kidney samples, tissues were homogenized into $200 \mu \mathrm{L}$ of RIPA buffer using a tissue glass Dounce homogenizer. Protein concentration was determined by the BCA Protein Assay. Samples were diluted into RIPA buffer, and $20 \mu \mathrm{g}$ was loaded for Western blot analysis.

\section{Immunocytochemistry and Confocal Microscopy}

Cells seeded onto eight-well Nunc Lab-Tek II Chambered Coverglass (Nalge Nunc International, Rochester, NY) were fixed with $4 \%$ paraformaldehyde in Dulbecco's modified PBS 
(DPBS) for 30 minutes at room temperature. After washing with DPBS, samples were blocked for 1 hour in DPBS containing $2 \mathrm{mg} / \mathrm{mL}$ bovine serum albumin, $1 \%$ fish gelatin, $5 \%$ goat serum, and $0.1 \%$ Triton X-100. Samples were then incubated for 1 hour with primary antibodies. After extensive washes with DPBS, the corresponding fluorescently labeled secondary antibodies and DAPI (Invitrogen) for nuclear staining were added for another hour. Samples were examined on an Olympus FV500-IX confocal laser-scanning microscope (Olympus Optical Co. Europe, Hamburg, Germany).

\section{IHC Analysis of Human Renal Samples}

To characterize SCAI expression patterns in clinical samples, formalin-fixed, paraffin-embedded samples were used. Renal tissues from core biopsy specimens were previously diagnosed in routine pathological examinations for different renal pathological conditions, and were retrieved from the 2nd Department of Pathology, Semmelweis University (Budapest, Hungary), after the approval of the Semmelweis University Ethical Board (TUKEB 5/2011). Samples were randomly selected for this study. A brief diagnostic description of samples is included in the respective figure legends.

Samples were fixed in $4 \%$ neutral-buffered formalin for 24 hours. Paraffin-embedded sections (3 to $4 \mu \mathrm{m}$ thick) were stained with rat monoclonal anti-SCAI obtained from Dr. Robert Grosse. Antigen retrieval was performed with $0.1 \mathrm{~mol} / \mathrm{L}$ citrate buffer, $\mathrm{pH}$ 6.0, in the microwave for 20 minutes. Blocking (Powerblock; BioGenex, Fremont, CA), secondary antibodies (Supersensitive Link; BioGenex), and alkalic phosphatase-conjugated streptavidin (BioGenex) were used according to the manufacturer's protocol. Samples were developed using Permanent Red Substrate-Chromogen (Dako). Nuclei were counterstained with Mayer's hematoxylin solution (Sigma). IHC reactivity was examined by light microscopy (Leica DMR HC; Leica Microsystems, Wetzlar, Germany).

\section{Induction of Diabetes Mellitus in Rats}

Male Sprague-Dawley rats, weighing 250 to $300 \mathrm{~g}$ (Charles River, Sulzfeld, Germany), were housed at a constant temperature of $22^{\circ} \mathrm{C} \pm 2{ }^{\circ} \mathrm{C}$ with 12-hour light-dark cycles, with access to standard rodent chow and water ad libitum. The investigation conforms to the Guide for the Care and Use of Laboratory Animals, published by the US NIH (publication 85-23, revised 1996). All procedures and handling of animals during the investigations were reviewed and approved by the local Ethical Committee for Animal Experimentation (22.1/4268/003/2009).

Type 1 diabetes mellitus was induced in rats with a single $60 \mathrm{mg} / \mathrm{kg}$ i.p. dose of streptozotocin (STZ). STZ was freshly dissolved in $0.1 \mathrm{~mol} / \mathrm{L}$ citrate buffer. Control animals received only the buffer. After 72 hours, the blood glucose concentration was determined using a digital blood glucose meter and test strips (Accu-Chek Sensor; Roche). Animals with a random blood glucose level of $>15 \mathrm{mmol} / \mathrm{L}$ were considered as diabetic and were included into the study (STZ group, $n=4$ ). Rats injected only with citrate buffer served as nondiabetic controls (control group, $n=4$ ).

Eight weeks after the induction of diabetes, rats were anesthetized with $100 \mathrm{mg} / \mathrm{kg}$ ketamine and $3 \mathrm{mg} / \mathrm{kg}$ xylazine i.p., and kidneys were removed for further analysis. A blood sample was taken from the inferior caval vein, and serum was prepared. Urine samples were obtained by sterile punction of the urinary bladder. Serum glucose and urea levels and urine creatinine concentration were determined by photometrical analysis on a Reflotron analyzer (Roche). Urine protein concentration was measured using the BCA Protein Assay, and urinary protein/creatinine ratios were calculated. Statistical analysis was performed by the $U$-test, with results being considered significant when $P<0.05$. Data are given as the mean \pm SD.

\section{IHC Analysis of Rat Kidneys}

Rat kidney tissue samples were processed as human renal samples, as described in IHC Analysis of Human Renal Samples. Immunohistological stains using antibody against SCAI (Sigma) were analyzed by two investigators (L.F. and G.K.) blinded with respect to the animal group using the following semiquantitative scoring system: 0 , no expression; 1, weak expression; 2, moderate expression; and 3, strong expression. Statistical analysis was performed by the $f$-test, with results being considered significant when $P<0.05$. Data are given as the mean \pm SEM.

\section{RT-qPCR Analysis of SCAI mRNA Expression in Diabetic Mice and mIMCD-3 Cells}

Diabetes was induced in male FVB/N mice $(n=8)$ obtained from Charles River at the age of 8 weeks, with daily i.p. injections of STZ [50 mg/kg, freshly dissolved in citrate buffer ( $\mathrm{pH} 4.5)$ ] for 5 days. Control mice $(n=7)$ received citrate buffer only. One week later, blood glucose levels were measured after 4 hours of fasting with Accu-Check test strips (Roche), and STZ-injected mice with a fasting blood glucose level $<20 \mathrm{mmol} / \mathrm{L}$ were excluded from the study $(n=3)$. Mice were sacrificed 8 weeks after the induction of diabetes, and kidneys were analyzed. The investigation conforms to the Guide for the Care and Use of Laboratory Animals, published by the US NIH (publication 85-23, revised 1996). All procedures and handling of animals during the investigations were reviewed and approved by the local Ethical Committee for Animal Experimentation (22.1/4263/003/2009).

For quantitative RT-PCR (RT-qPCR) experiments, $100 \mathrm{mg}$ of whole kidneys was homogenized and total RNA was isolated according to the manufacturer's protocol (SV Total RNA Kit; Promega). A total of $2 \mu \mathrm{g}$ of RNA was reverse transcribed (High Capacity cDNA Reverse Transcription Kit; Applied Biosystems, Foster City, CA) using random primers. PCRs were performed on a BioRad CFX thermal cycler (BioRad, 
Hercules, CA) using the Maxima SYBR Green PCR Master Mix (Thermo Scientific) and $95^{\circ} \mathrm{C}$ for 15 seconds and $60^{\circ} \mathrm{C}$ for 60 seconds for 40 cycles. The specificity and efficiency of the PCR was confirmed with melting curve and standard curve analysis, respectively. Duplicate samples were normalized to GAPDH expression. Mean values are expressed with the following formula: $2^{\Delta \Delta \mathrm{C}_{\mathrm{T}}}$. Primer sequences were as follows: SCAI， 5'-ACCCCTGTTCATCGTTGTG-3' (forward) and 5'-CGAGTGGCTGTCCAAACAA- $3^{\prime}$ (reverse); and GAPDH, $5^{\prime}$-CTTTGTCAA-GCTCATTTCCTGG-3' (forward) and 5'-TCTTGCTCA-GTGTCCTTGC-3' (reverse). Results are given as mean $\pm \mathrm{SD}$.

The mIMCD-3 cells were plated onto six-well plates and subjected to treatments. After the treatments, cells were washed once with PBS and total RNA was isolated using TRIzol (Invitrogen), following the instructions of the manufacturer. Reverse transcription and RT-PCR were performed as above. Three parallels were measured for each treatment, and the experiment was repeated two times.

\section{UUO in Mice}

Male C57BL/6 mice, obtained from Charles River, were bred at the animal facility of Semmelweis University. Animals were kept on regular rodent chow and given water ad libitum. All animal experiments were performed according to the institutional regulations, the Hungarian law on animal care and protection [1998/XVIII, 243/1998(XII.31)], and were approved by the local Ethical Committee for Animal Experimentation (22.1/4261/003/2009).

Mice weighing a mean \pm SD of $25.5 \pm 2.0 \mathrm{~g}$ were anesthetized by an i.p. injection of a cocktail containing ketamine $(100 \mathrm{mg} / \mathrm{kg}$ body wt.) and xylazine $(8 \mathrm{mg} / \mathrm{kg}$ body wt.). Eight mice were subjected to UUO. Kidneys were accessed from a median laparotomy. The left ureter was ligated below the renal hilum to achieve complete obstruction using a 6.0 silk suture. The abdominal wound was closed, and mice were observed for 14 days.

Mice were harvested on day 14 after UUO, as previously described. ${ }^{30}$ Harvesting began with ether anesthesia (Reanal, Budapest, Hungary) and heparinization (Sandoz, Holzkirchen, Germany) of mice. Blood was taken from the vena cava superior, and plasma was separated by centrifugation of heparinized blood at $4^{\circ} \mathrm{C}$ and $400 \times g$ for 10 minutes. Mice were perfused with $20 \mathrm{~mL}$ of ice-cold HBSS (Sigma-Aldrich), administered through the left ventricle using a $20-\mathrm{mL}$ syringe and an 18-gauge needle. Obstructed left and unobstructed right kidneys were excised, and renal tissue was collected. Samples were prepared and analyzed by using Western blot analysis.

\section{Results}

\section{SCAI Expression in LLC-PK1 Cells}

SCAI mRNA is expressed in kidney as well; however, there were no data regarding the SCAI protein expression pattern in proximal tubular epithelial cells. The subcellular localization of SCAI was determined in LLC-PK1 cells. When endogenous SCAI was stained or GFP-tagged SCAI was expressed in these cells, SCAI was enriched mainly in the nuclei of LLC-PK1 cells, and cytoplasmic expression was characteristic to a lesser degree. The GFP-tagged N-terminally truncated version of SCAI (GFP-SCAI $\Delta$ nt), on the other hand, was enriched in the cytoplasm; its nuclear expression was less pronounced (Figure 1).

\section{SCAI Inhibits TGF- $\beta 1-$ Induced SMA Promoter}

Activation and Protein Expression in LLC-PK1 Cells, Inhibits Calponin and CTGF Expression, and Prevents TGF- $\beta 1$-Induced E-Cadherin Down-Regulation

We next addressed the potential involvement of SCAI in the regulation of TGF- $\beta 1$-induced SMA promoter activation and protein expression.

Transient transfection and luciferase assays were performed to study the effects of SCAI expression on TGF$\beta 1$-induced SMA promoter activation. As previously found, TGF- $\beta 1$ induced a fivefold increase in SMA promoter activity in nonconfluent LLC-PK1 cells. Cotransfection and expression of SCAI inhibited TGF- $\beta 1$-induced SMA promoter activation. Noticeably, GFP-SCAI $\Delta$ nt did not show this marked inhibitory effect (Figure 2A). We showed earlier that a $\mathrm{Ca}^{2+}$ deprivation-induced increase in promoter activity was also MRTF dependent. ${ }^{8}$ Therefore, we tested whether SCAI influenced the effects of this stimulus.

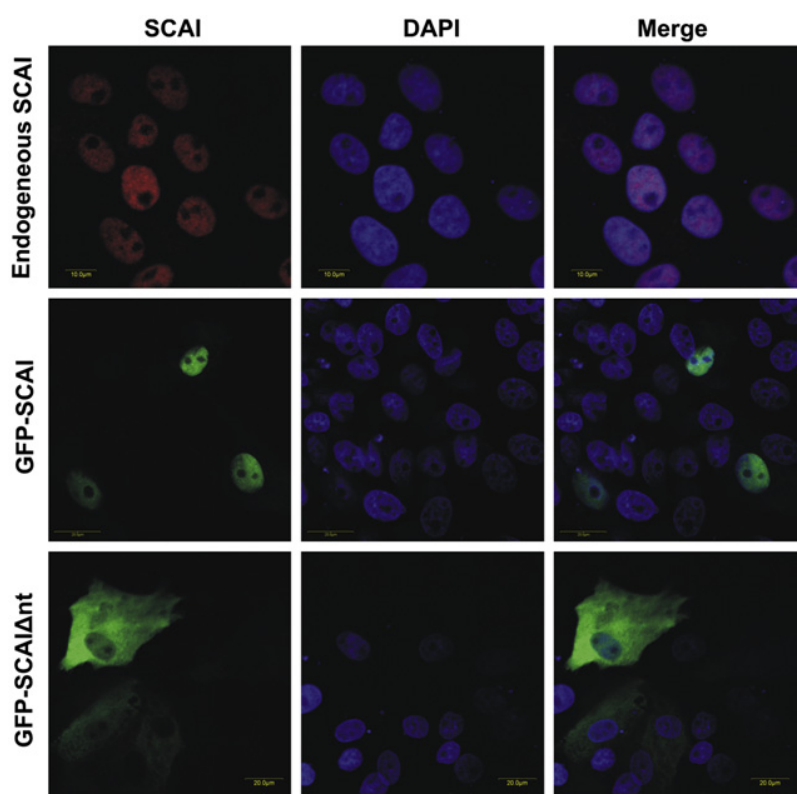

Figure 1 Localization of SCAI in LLC-PK1 cells. Endogenous SCAI is localized in the nuclei of LLC-PK1 cells. Cells were stained for endogenous SCAI as described in Materials and Methods and analyzed by confocal microscopy. Transfection of GFP-SCAI also led to the enrichment of SCAI in the nuclei of LLC-PK1 cells, whereas the SCAI $\Delta$ nt version of the construct was accumulated predominantly in the cytoplasm. Transfected cells were fixed and examined by confocal microscopy. 
SMA-Luc-transfected confluent cells yielded an eightfold increase on $\mathrm{Ca}^{2+}$ deprivation, and this effect was reduced by approximately $25 \%$ when GFP-SCAI was overexpressed (Figure 2B), indicating that SCAI might, in part, interfere with this stimulation.

Immunofluorescence staining and confocal microscopy were applied to examine the potential impact of SCAI on SMA protein expression. Cells were transfected with GFPSCAI, and treated with TGF- $\beta 1$ for 3 days. Under similar conditions, approximately $20 \%$ to $22 \%$ of LLC-PK 1 cells expressed SMA on TGF- $\beta 1$ treatment. In this experiment, most cells expressing SCAI were not positive for SMA (Figure 2C): only $<2 \%$ of GFP-SCAI-transfected cells were positive for SMA on TGF- $\beta 1$ stimulation, an indication that SCAI inhibited SMA protein expression. SMA expression was also assessed in cells transfected with GFPSCAI $\Delta$ nt and stimulated with TGF- $\beta 1$ : approximately $26 \%$ of cells transfected with GFP-SCAI $\Delta$ nt were SMA positive (data not shown).

To obtain a more detailed view on the inhibition of SMA expression by SCAI, LLC-PK1 cells stably expressing GFPSCAI were generated by transfection and three subsequent rounds of GFP-based cell sorting. The stable cells were almost completely positive for GFP-SCAI. Subconfluent LLC-PK1 and LLC-PK1/SCAI cells were then treated with TGF- $\beta 1$ for 3 days, and analyzed by using Western blot analysis. In LLC-PK1 cells, 3 days of TGF- $\beta 1$ treatment resulted in a robust expression of SMA, whereas in
LLC-PK1/SCAI SMA protein expression was almost entirely abolished (Figure 3A). To further test the extent of the involvement of SCAI in EMT and renal fibrosis, other CArG-driven markers were also analyzed. First, calponin expression was also decreased in TGF- $\beta 1$-treated LLC-PK1/SCAI cells (Figure 3B). SCAI prevented TGF- $\beta 1$-induced E-cadherin down-regulation and SCAI rescued E-cadherin expression in TGF- $\beta 1$-treated LLCPK1/SCAI cells (Figure 3C). TGF- $\beta 1$-induced CTGF expression is a well-known CArG-dependent renal fibrosis marker. ${ }^{16,31,32}$ TGF- $\beta 1$ induced CTGF expression in LLCPK1 cells, which was inhibited in LLC-PK1/SCAI cells (Figure 3D). These results indicated that SCAI was involved in the regulation of SMA promoter and SMA protein expression, and that SCAI was an endogenous inhibitory cofactor that controlled expression of certain CArGdependent TGF- $\beta 1$ target genes.

\section{SCAI Prevents SMA Promoter Activation Induced by MRTF-A and MRTF-B and by RhoA, Rac1, and Cdc42}

Because SMA expression is dependent on MRTFs, next we assessed whether SCAI interfered with MRTF-A- and MRTF-B-induced SMA promoter activation. Therefore, we stimulated SMA promoter with MRTF-A or MRTF-B in the presence or absence of GFP-SCAI. The robust activation of the promoter induced by MRTF-A and MRTF-B was abolished by SCAI cotransfection, indicating the MRTF
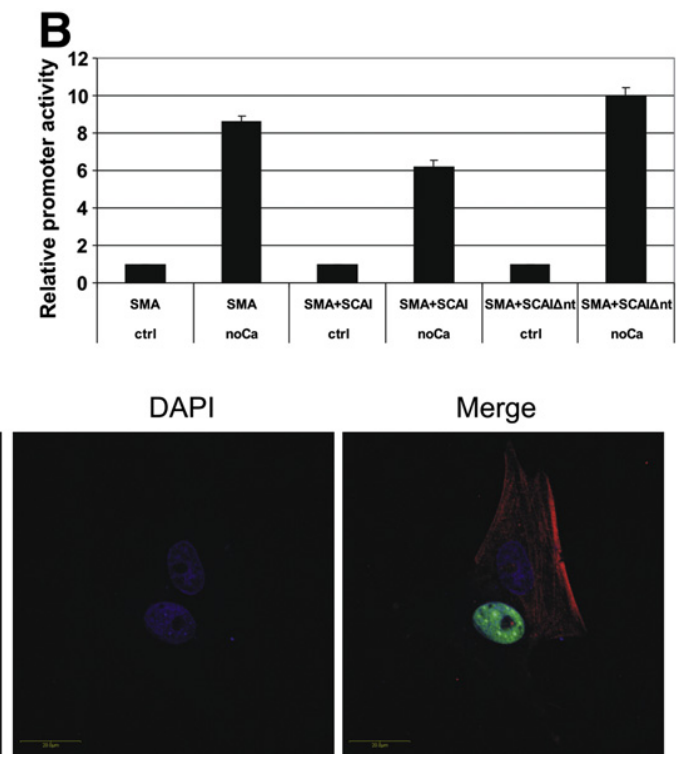

Figure 2 SCAI inhibits TGF- $\beta 1$-induced SMA promoter activation and protein expression in LLC-PK1 cells. A: SCAI inhibits TGF- $\beta 1$-induced SMA promoter activation, as shown by luciferase assays. Cells were transfected with SMA promoter with or without GFP-SCAI or GFP-SCAI $\Delta$ nt and were treated with TGF- $\beta 1$. SCAI, but not SCAI $\Delta \mathrm{nt}$, inhibited the activation of the SMA promoter induced by TGF- $\beta 1$ (SCAI, $4.96 \pm 0.33$ versus $2.31 \pm 0.13$; SCAI $\Delta$ nt, $4.96 \pm 0.33$ versus $4.18 \pm$ 0.47). B: SCAI inhibits SMA promoter activation induced by cell contact disruption, as shown by luciferase assays. Cells were transfected with SMA promoter with or without GFP-SCAI or GFP-SCAI $\Delta$ nt and were treated with low $\mathrm{Ca}^{2+}$-containing medium to achieve the disruption of cell contacts. SCAI, but not SCAI $\Delta$ nt, reduced the activation of the SMA promoter induced by cell contact disruption (SCAI, $8.57 \pm 0.31$ versus $6.18 \pm 0.35 ;$ SCAI $\Delta$ nt, $8.57 \pm 0.31$ versus $10.02 \pm$ 0.41). C: SCAI inhibits TGF- $\beta 1$-induced SMA protein expression. Cells were transfected with GFP-SCAI and were treated with TGF- $\beta 1$ for 3 days, after 24 hours. Cells were then fixed, stained as indicated in Materials and Methods, and visualized by confocal microscopy. Only approximately $2 \%$ of SCAI-transfected cells were positive for SMA, whereas the non-transfected population was approximately $20 \%$ positive for SMA. To quantify the effect, three separate experiments were performed, in which 240 randomly selected control (non-transfected) cells and 106 GFP-SCAI-transfected cells were assessed for SMA expression. 


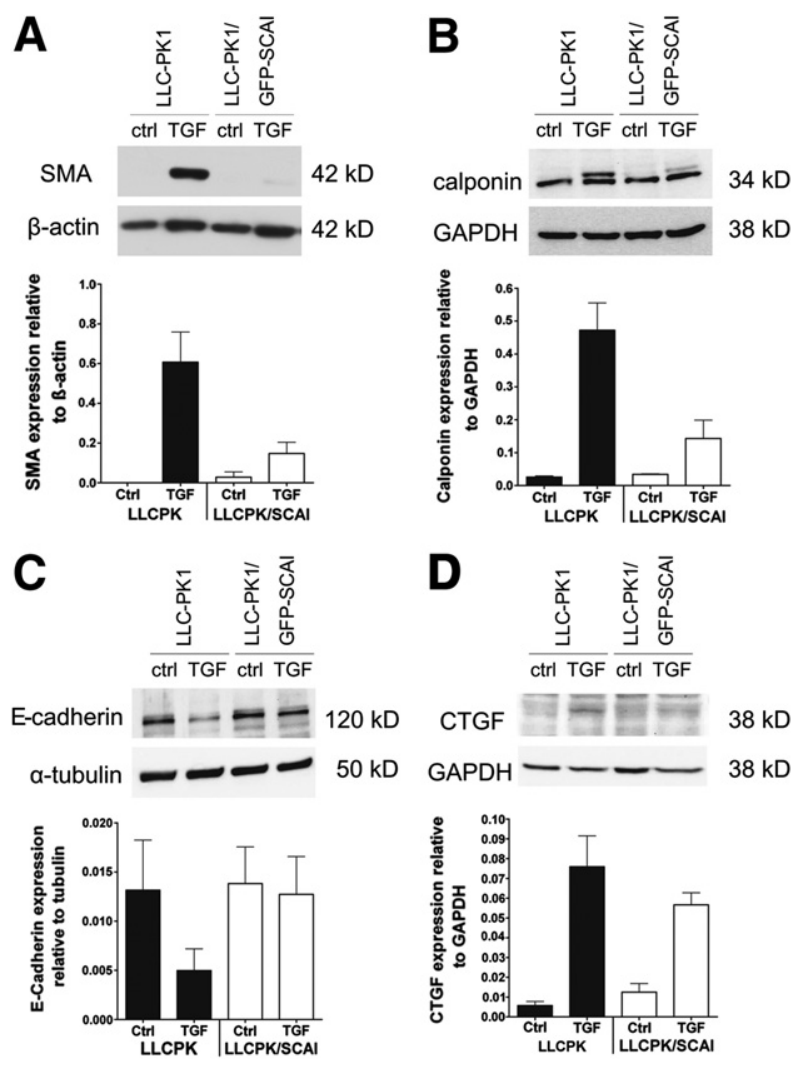

Figure 3 SCAI interferes with TGF- $\beta 1$-induced SMA, calponin, and CTGF expression, and rescues E-cadherin expression in LLC-PK1 cells stably expressing SCAI. A: SCAI inhibits TGF- $\beta 1-$ induced SMA protein expression. An LLC-PK1 cell line stably expressing GFP-SCAI was generated as described in Materials and Methods. Subconfluent LLC-PK1 and LLC-PK1/GFP-SCAI cells were treated with TGF- $\beta 1$ for 3 days, and were then analyzed by using Western blot analysis. SMA protein expression in the cells stably expressing SCAI was inhibited (LLC-PK + TGF versus LLC-PK/SCAI + TGF, $0.6 \pm 0.15$ versus $0.15 \pm 0.05)$. B: Three days of TGF- $\beta 1$ treatment induced calponin expression in LLC-PK1 cells. SCAI inhibited calponin expression (LLC-PK + TGF versus LLC-PK/SCAI/TGF, $0.47 \pm 0.08$ versus $0.14 \pm 0.05)$. C: TGF- $\beta 1$ treatment led to the down-regulation of E-cadherin expression in LLC-PK1 cells. SCAI rescued E-cadherin expression (LLC-PK + TGF versus LLC-PK/ $\mathrm{SCAI}+\mathrm{TGF}, 0.005 \pm 0.002$ versus $0.01 \pm 0.003)$. D: TGF- $\beta 1$-induced CTGF expression was reduced in LLC-PK1/SCAI cells (LLC-PK + TGF versus LLC-PK/SCAI + TGF, $0.07 \pm 0.01$ versus $0.05 \pm 0.006)$.

specificity of SCAI-dependent inhibition of the SMA promoter (Figure 4, A and B).

SMA promoter was regulated by several signaling molecules, such as RhoA, Rac1, and $\mathrm{Cdc} 42$, belonging to the family of small GTPases, in an MRTF-SRF-dependent manner. Cotransfection and expression of the constitutively active forms of these molecules induced the activation of the SMA promoter. The initial activation induced by these small GTPases was strongly inhibited by the expression of wildtype GFP-SCAI (Figure 4, C-E). These results indicated that, as expected, SCAI inhibited the SMA activation signals that were dependent on MRTF and SRF. Based on these results, SCAI emerged as a master inhibitory regulator of TGF- $\beta 1$-induced, SRF- and MRTF-dependent SMA expression.
SCAI Prevents SMA Promoter Activation Induced by TGF- $\beta 1$, MRTF-A, and MRTF-B in a CArG-Dependent Manner

MRTFs regulate the SMA promoter in a CArG domaindependent manner. To test whether SCAI interfered with SMA promoter activation via CArG domains, we Zused the p152-SMA-Luc promoter construct, which contains a 152-bp long sequence of the SMA promoter containing the two CArGs and the TGF- $\beta$ control element, but lacking both Smad-binding elements and the E-box. Cotransfection and expression of SCAI inhibited TGF- $\beta 1$-induced 152-bp SMA promoter activation (Figure 5A). The activation of the 152-bp SMA promoter induced by MRTF-A and MRTF-B was inhibited by SCAI cotransfection (Figure 5, $\mathrm{B}$ and $\mathrm{C}$ ). These results indicated the $\mathrm{CArG}$ domain specificity of SCAI-dependent inhibition of the SMA promoter.

\section{TGF- $\beta 1$ Attenuates SCAI Protein and mRNA Expression}

Next, we assessed whether TGF- $\beta 1$ could influence SCAI protein expression. Control LLC-PK1 cells and LLC-PK1 cells subjected to 3 days of TGF- $\beta 1$ treatment were analyzed by using Western blot analysis. TGF- $\beta 1$ treatment of LLC-PK1 cells induced the attenuation of SCAI (Figure 6, A and B). Furthermore, 12 hours of TGF- $\beta 1$ treatment led to a decrease of SCAI mRNA in mIMCD-3 cells, as found in RT-PCR experiments (Figure 6C). These results indicated that TGF- $\beta 1$ could modulate SCAI mRNA and protein expression in vitro.

\section{IHC Analysis of SCAI Expression Patterns in Human Kidneys}

To substantiate our in vitro findings on the potential role of SCAI, we proposed to characterize renal SCAI protein expression patterns by IHC analysis of human kidney samples.

We proposed to investigate the expression pattern of SCAI protein in normal kidneys. In normal renal tissue, SCAI expression was present as early as in embryonic kidneys: SCAI was expressed both in glomerular and tubular cells (Figure 7A). In adult kidneys, SCAI was expressed both in glomerular cells and podocytes (Figure 7B). Proximal tubular cells expressed SCAI mainly in nuclei (Figure 7C). Vascular smooth muscle cells weakly expressed SCAI; however, endothelial cells were positive for SCAI (Figure 7D).

In fibrotic kidneys, the widened interstitial space contained SCAI-negative cellular elements, and affected tubular cells stained weaker for SCAI (Figure 8A). Sclerotic glomeruli lost SCAI positivity (Figure 8B), and tubular cells even showed severe loss of SCAI expression (Figure 8C).

Next, we examined SCAI expression in renal cell carcinomas. As expected, the tumor cells in renal cell carcinomas did not express SCAI (Figure 9A). In contrast to renal cell 
carcinomas, blastemic Wilms' tumor was found positive for SCAI, with some cells showing highly enriched nuclear expression in cells with oval nuclei and scanty cytoplasm (Figure 9B).

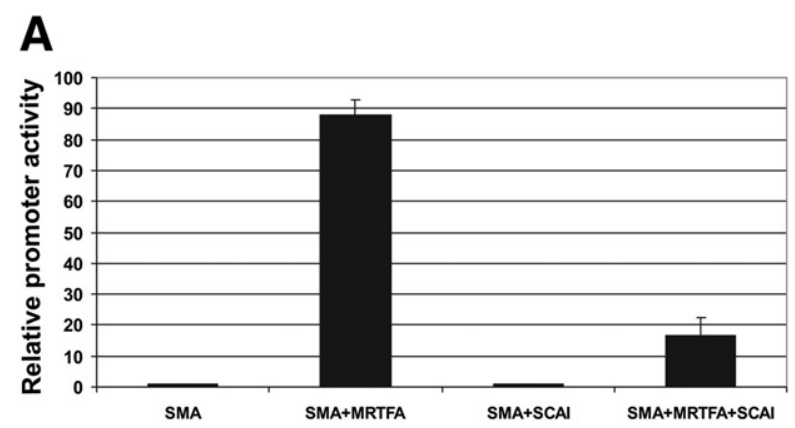

B


E



Diabetic Nephropathy in Rats Leads to a Significant Decline in Renal SCAI Protein Expression

To further characterize SCAI expression in diseased kidneys and to obtain quantitative data on SCAI expression patterns in fibrotic renal disease, in vivo studies were performed. Diabetes was induced by STZ in male Sprague-Dawley rats, and 8 weeks after the induction of diabetes, control and diabetic kidneys were assessed by IHC. Diabetes is wellknown to induce diabetic nephropathy through renal fibrosis with the involvement of TGF- $\beta 1$. We used this model to investigate the possible link between fibrosis and a potential decline in SCAI expression in the kidney.

The induction of diabetes led to a significantly elevated urine protein/creatinine ratio, elevated serum glucose and elevated serum urea levels in diabetic rats compared with nondiabetic controls [urine protein/creatinine ratio $(\mathrm{mg} / \mathrm{mg})$ : control, $6.4 \pm$ 0.6; STZ, $51.3 \pm 8.0$; serum glucose (mg/dL): control, 256.16 \pm 75.5 ; STZ, $911.14 \pm 239.4$; serum urea $(\mathrm{mg} / \mathrm{dL})$ : control, $31.68 \pm 5.5 ;$ STZ, $45.51 \pm 12.1]$. Diabetic animals developed glomerular and tubulointerstitial damage characterized by mesangial expansion and tubular atrophy, hyaline deposits, and mild mononuclear cell infiltration, corresponding to findings in an early phase of nephropathy. Tubular cells in control kidneys (Figure 10A) showed more intense nuclear SCAI staining than tubular cells in diabetic kidneys (Figure 10B). Intercalated cells stained similarly in both cases. When tubular SCAI stainings were compared, control kidneys stained significantly stronger than diabetic kidneys $(1.273 \pm 0.118$ versus $0.697 \pm 0.07 ; P=0.03$ ) (Figure 10C).

To substantiate our findings, we next performed Western blot analyses to test whether there was an inverse relationship of SCAI and SMA or calponin expression in control and diseased kidneys using control and diabetic rat medullas. There was an inverse relationship between SCAI and SMA or calponin expression: SCAI tended to be more elevated in control samples, and its expression level declined in kidneys affected by diabetic nephropathy, whereas SMA and calponin expression was more pronounced in diabetic samples (Figure 10, D-F).

\section{SCAI mRNA Is Down-Regulated in Kidneys of Diabetic Mice}

Next, SCAI mRNA expression patterns were characterized in kidneys of diabetic mice. Type 1 diabetes mellitus was

Figure 4 SCAI prevents SMA promoter activation induced by MRTF-A, MRTF-B, RhoA, Rac1, and Cdc42. A-E: Cells were transfected with SMA promoter and MRTF-A, MRTF-B, constitutive active RhoA, constitutive active Rac1, or constitutive active Cdc42, respectively, and luciferase assays were performed. SCAI prevented SMA promoter activation induced by MRTF-A ( $87.97 \pm 5.04$ versus $16.53 \pm 5.78)$, MRTF-B $(68.61 \pm 15.33$ versus $16.43 \pm 1.54)$, constitutive active RhoA (10.57 \pm 0.69 versus $3.59 \pm$ $0.41)$, constitutive active $\operatorname{Rac} 1(3.69 \pm 0.39$ versus $1.25 \pm 0.12)$, and constitutive active Cdc42 (10.71 \pm 1.02 versus $5.43 \pm 0.43)$. 

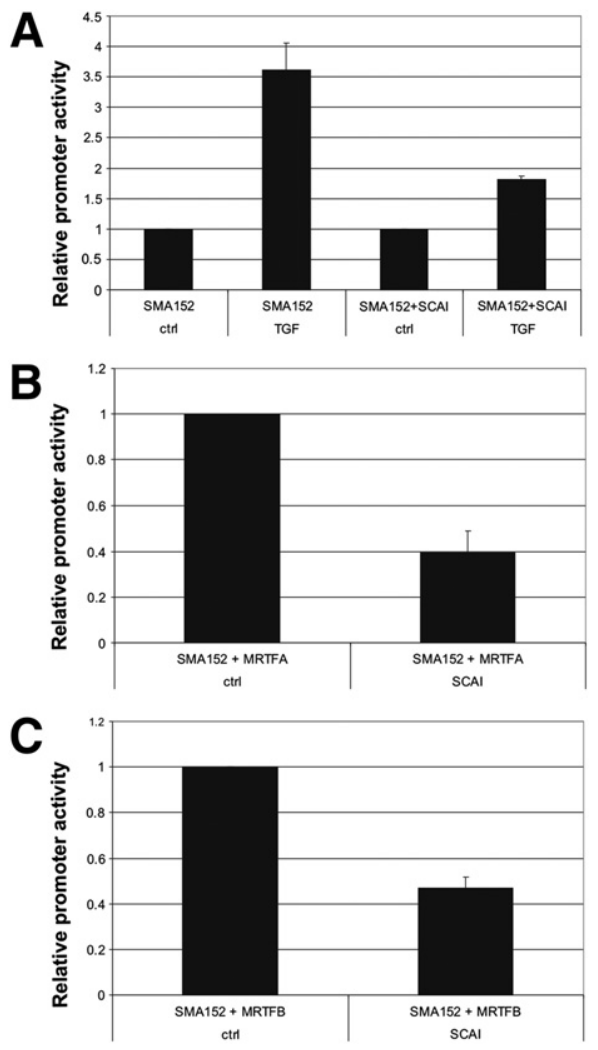

Figure 5 SCAI prevents SMA promoter activation induced by TGF- $\beta 1$, MRTF-A, and MRTF-B in a CArG-dependent manner. A: SCAI inhibits TGF- $\beta 1$-induced activation of the 152-bp long SMA promoter sequence containing the two CArGs and the TGF- $\beta$ control element, but lacking both Smad-binding elements and the E-box using luciferase assays. Cells were transfected with p152-SMA-Luc promoter with or without GFP-SCAI and were treated with TGF- $\beta 1$. SCAI inhibited the activation of the 152-bp SMA promoter induced by TGF- $\beta 1$ (3.61 \pm 0.44 versus $1.81 \pm 0.05)$. B: Cells were transfected with p152-SMA-Luc promoter, and MRTF-A and luciferase assays were performed. SCAI overexpression led to a $60 \%$ decrease of $\mathrm{p} 152-$ SMA promoter activation induced by MRTF-A. C: Cells were transfected with p152-SMA-Luc promoter, and MRTF-B and luciferase assays were performed. SCAI overexpression led to a 53\% decrease of p152-SMA promoter activation induced by MRTF-B. ctrl, control.

induced in FVB/N mice, and RNA was isolated from $100 \mathrm{mg}$ of whole kidneys. After reverse transcription, SCAI cDNA levels were assessed by RT-qPCR, and GAPDH was used as an internal control, with results being normalized to GAPDH cDNA levels. Similarly to SCAI expression patterns in different malignant tissues, ${ }^{27}$ we found that SCAI mRNA was markedly and significantly down-regulated in kidneys of diabetic mice $(0.59 \pm 0.23$ versus $0.28 \pm 0.10 ; P=0.01)$ (Figure 10G), in concordance with findings on SCAI protein expression patterns in fibrotic kidneys.

\section{Decreased SCAI Protein Expression in UU0 Kidneys}

To substantiate our in vivo findings on SCAI expression patterns, we evaluated SCAI expression in a model of UUO in mice. UUO is a widely used model of renal interstitial fibrosis and obstructive nephropathy, generating progressive renal fibrosis. We performed the experiment on male
C57BL/6 mice. UUO kidneys and contralateral kidneys from the same animals were compared by using Western blot analysis. SCAI expression was attenuated in UUO kidneys, when compared with the contralateral control kidneys. In parallel with the decreasing SCAI expression, robust SMA expression was observed in UUO kidneys (Figure 11, A-C).

Finally, the UUO sample set was probed with a second SCAI antibody. Similar results were obtained with both antibodies, an indication that both antibodies recognized the SCAI protein (Figure 11D).

\section{Discussion}

The complex regulation of EMTs during cancer progression and fibrosis is achieved by several similar signaling events.
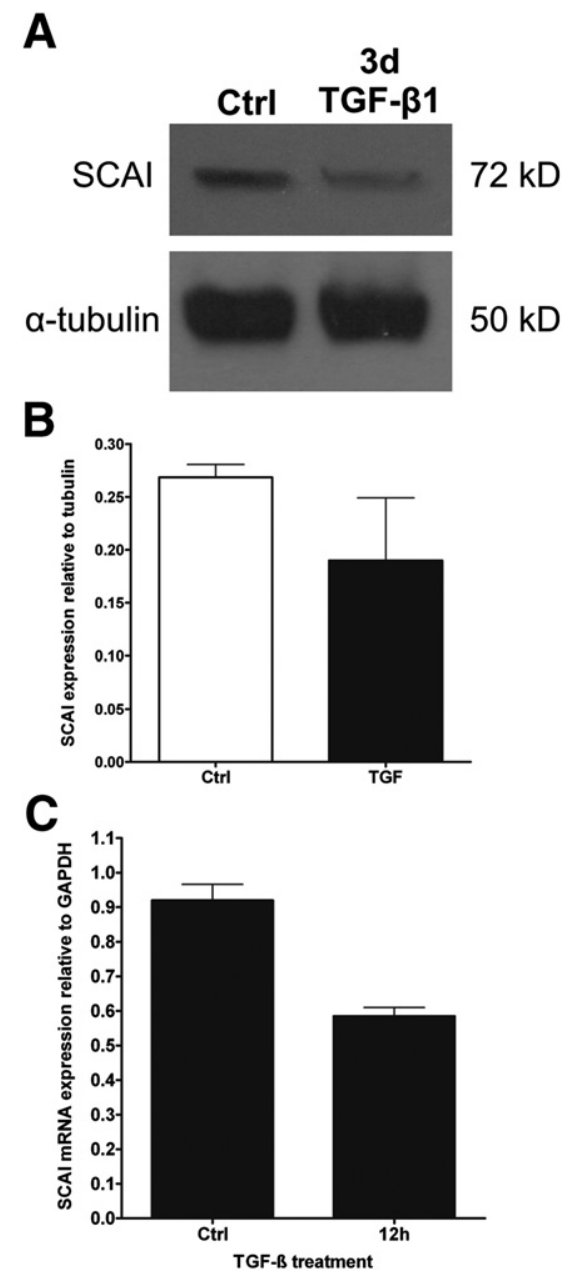

Figure 6 TGF- $\beta 1$ attenuates SCAI protein expression in LLC-PK1 cells and SCAI mRNA expression in mIMCD-3 cells. A and B: LLC-PK1 cells were subjected to 3 days of TGF- $\beta 1$ treatment and were analyzed by using Western blot analysis. TGF- $\beta 1$ treatment led to an attenuation of SCAI expression in LLC-PK1 cells. Quantification of the Western blot experiment is as follows: control (Ctrl), $0.27 \pm 0.01 ;$ TGF, $0.19 \pm 0.06$. C: mIMCD cells were treated with TGF- $\beta 1$ for 12 hours, and after RNA isolation and reverse transcription, RT-qPCR was performed. TGF- $\beta 1$ decreased SCAI mRNA expression (0.92 \pm 0.05 versus $0.58 \pm 0.02 ; P=0.01$ ). 



Figure 7 SCAI protein expression patterns in normal renal tissues. A: Embryonic kidneys (from a 20-week-old fetus) express SCAI in the nuclei of glomerular and tubular cells. B: SCAI is expressed in both glomerular cells and podocytes, and podocytes show more intense nuclear staining (normal renal tissue area from a 4-year-old male patient with a Wilms' tumor). C: Proximal tubular cells express SCAI in nuclei (normal renal tissue area from a 64-year-old patient with a renal cell carcinoma). D: Vascular smooth muscle cells weakly expressed SCAI. The endothelial cells were positive for SCAI (normal renal tissue area from a 64-year-old patient with a renal cell carcinoma). Original magnification: $\times 200($ A) $; \times 400($ B - D) .

One such mechanism recently identified is the involvement of MRTF, both during fibrotic EMT and metastasis. ${ }^{8,17,26}$ SCAI inhibits the activity of MRTF, the cofactor of the transcription factor SRF, and it suppresses cancer cell invasion by negatively regulating $\beta_{1}$-integrin. Therefore, we wanted to determine the potential inhibitory role of SCAI in
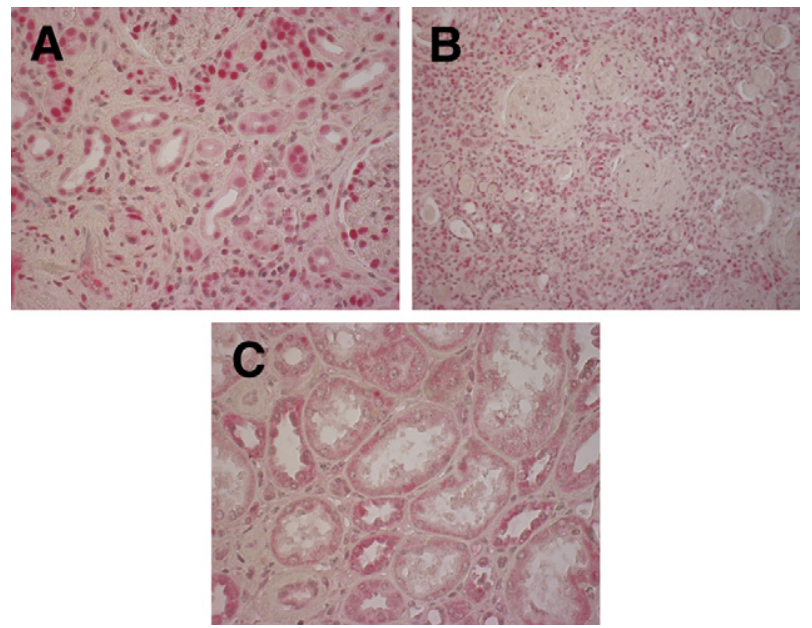

Figure 8 SCAI protein expression patterns in sclerotic renal tissues. A: A widened interstitial space contained SCAI-negative cellular elements, and the affected tubuli stain weaker for SCAI than the more intact tubular structures (nephrosclerosis and chronic pyelonephritis; 61-year-old female patient). B: Sclerotic glomeruli are negative for SCAI expression (arteriosclerotic nephrosclerosis and chronic pyelonephritis; 70-year-old male patient). C: Tubular area that lost SCAI positivity (arteriosclerotic nephrosclerosis and chronic pyelonephritis; 70 -year-old male patient). Original magnification: $\times 400($ A and C); $\times 200($ B $)$.
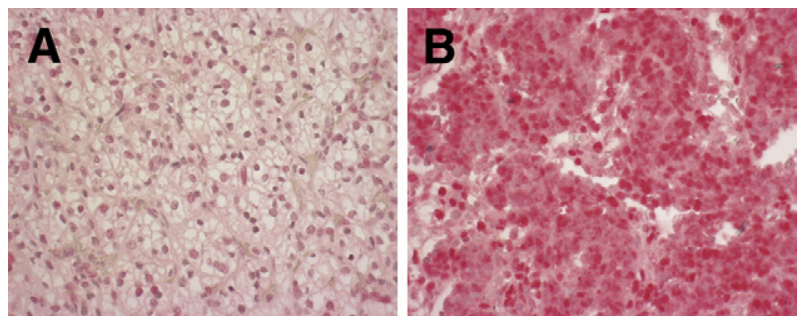

Figure 9 SCAI protein expression in renal tumors. A: A renal cell carcinoma (Fuhrman grade III; 60-year-old male patient) is negative for SCAI expression. B: A blastemic Wilms' tumor (high-risk type; 4-year-old male patient) shows strong SCAI positivity. Original magnification: $\times 400$ ( $A$ and $\mathbf{B})$.

TGF- $\beta 1$-induced SMA expression in a tubular model of EMT and to test whether SCAI interferes with the SMA promoter-activating effects of various signaling molecules, such as MRTFs or small Rho GTPases.

Our results indicate that SCAI inhibited TGF- $\beta 1$-dependent SMA promoter activation and protein expression, and partially decreased the effect of cell contact disruption on the promoter. It also prevented the activation of the promoter induced by MRTFs and small Rho GTPases. In sclerotic human kidneys, SCAI was not expressed in the cells forming the fibrotic tissue; moreover, in an in vivo model of diabetic nephropathy and in UUO kidneys, SCAI expression was significantly reduced compared with control kidneys. In fibrotic kidneys, the level of SCAI mRNA was downregulated, when compared with nonfibrotic kidney samples. One of the major triggers of fibrosis, TGF- $\beta 1$, down-regulated SCAI expression in vitro. In our model, SCAI may interfere with the expression of several CArG/MRTF-dependent proteins induced by different stimuli, such as TGF- $\beta 1$, whereas SCAI expression might be TGF- $\beta 1$ dependent as well, an observation that still needs to be investigated (Figure 12).

SCAI emerged as an endogenous inhibitory cofactor that regulates TGF- $\beta 1-$ dependent SMA expression. The SMA promoter contains CArG domains, ${ }^{33}$ and specific MRTF effects are linked to these domains. ${ }^{34}$ TGF- $\beta 1$ induces nuclear translocation of MRTF, and specific inhibition of MRTF prevented SMA expression. ${ }^{8,17}$ This mechanism may explain how SCAI, as an endogenous inhibitory cofactor of MRTF, can interfere with these signals. This hypothesis is supported by the TGF- $\beta 1$-induced down-regulation of SCAI, and, as such, removal of an important hurdle preventing SMA expression.

An obvious question is whether these effects are in any way restricted to the myogenic program of EMT. A completed EMT, after the decline of the epithelial program and the activation of a mesenchymal fibrogenic program, culminates in a myogenic program. ${ }^{6,35}$ To evaluate the extent of SCAI-dependent regulation of EMT, CArGdependent markers corresponding to the three programs were assessed.

SCAI rescued E-cadherin expression, which is downregulated on TGF- $\beta 1$ treatments. MRTF induced the 




C
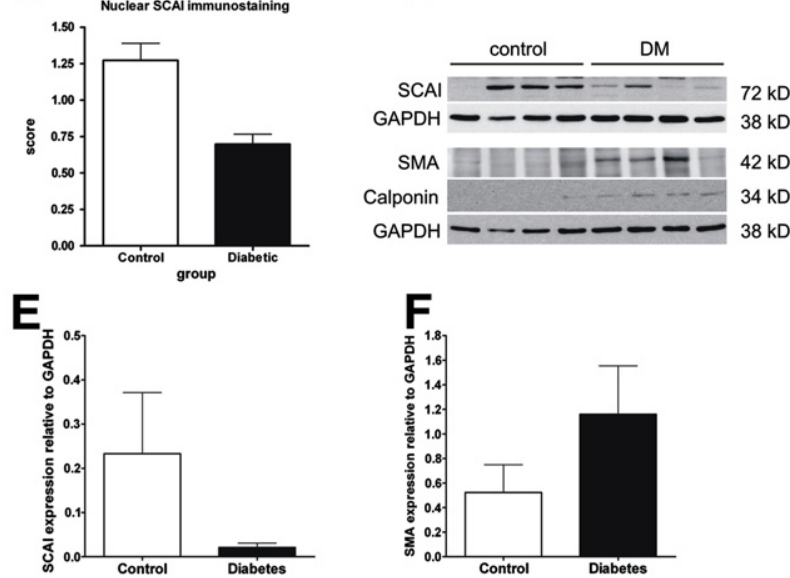

G

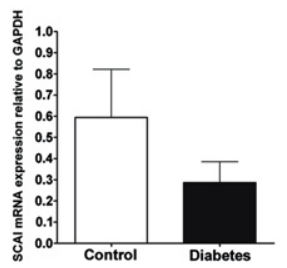

Figure 10 SCAI protein expression is significantly down-regulated in diabetic nephropathy. A: Tubular cells from control rat kidneys displayed intense SCAI staining, whereas intercalated cells stained more intensely. Arrows indicate examples of intense nuclear staining in tubular cells. B: Tubular cells from diabetic rat kidneys displayed weaker SCAI staining, whereas intercalated cells stained similarly as in control samples. Arrows indicate examples of weak or negative nuclear staining of tubular cells. Original magnification: $\times 630$ (A and B). C: Comparison and statistical analysis of SCAI IHC stainings from control and diabetic rat kidneys: kidneys from control rats stained significantly stronger than kidneys from diabetic rats $(1.273 \pm 0.118$ versus $0.697 \pm 0.07 ; P=0.03)$. D: Western blot analysis was performed to test for the inverse relationship between SCAI and SMA or calponin. Rat kidney medullas from control and diabetic animals were analyzed. SCAI tends to be more elevated in control samples, and its expression level declines in kidneys affected by diabetic nephropathy, whereas SMA and calponin expression were more pronounced in diabetic samples. E: Quantification of SCAI protein expression in control and diabetic rat kidney medullas based on using Western blot analysis: control, $0.23 \pm$ 0.14; diabetes mellitus (DM), $0.02 \pm 0.009$. F: Quantification of SMA protein expression in control and diabetic rat kidney medullas based on using Western blot analysis: control, $0.52 \pm 0.22 ;$ DM, $1.16 \pm 0.39$. G: SCAI mRNA is down-regulated in kidneys of diabetic mice. RT-qPCR analysis showed a significant decrease of SCAI mRNA expression in kidneys of diabetic FVB/N mice when compared with normal control kidneys. Results were normalized to GAPDH $(0.59 \pm 0.23$ versus $0.28 \pm 0.10 ; P=0.01)$.

down-regulation of E-cadherin in MDCK cells. ${ }^{36}$ It is wellknown that an important regulator of EMT is Slug, which down-regulates E-cadherin. The trigger of this mechanism, Slug, is under the control of MRTF via a GCCG-like

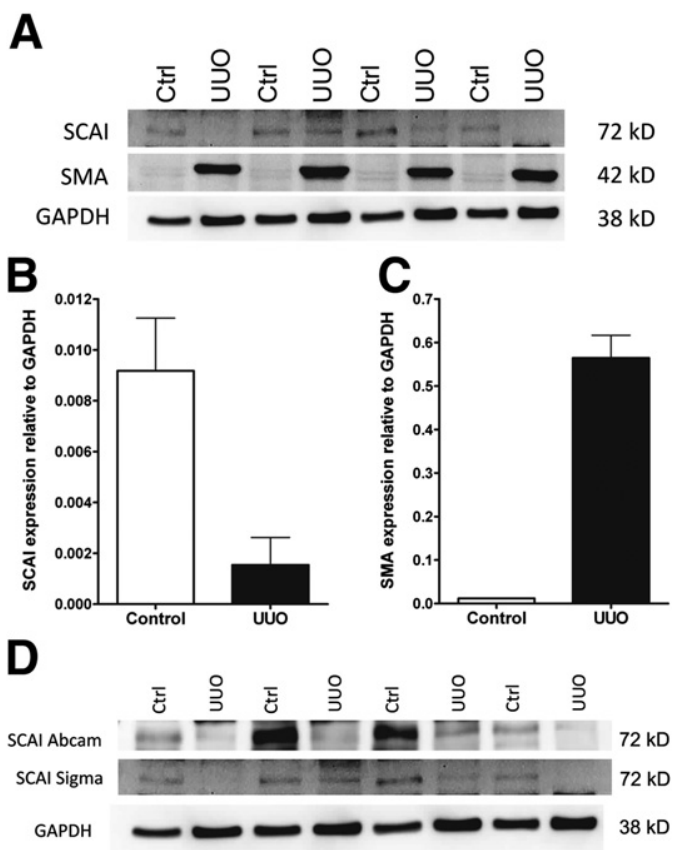

Figure 11 Decreased SCAI expression in UU0 kidneys. A: C57BL/6 mice were subjected to UU0, with contralateral kidneys serving as a control (Ctrl). SCAI expression was reduced in UUO kidneys, as evidenced by using Western blot analysis. Parallel to the decrease in SCAI expression on UUO, UUO kidneys presented robust SMA expression. B: Quantification of SCAI protein expression in control and UUO kidneys, based on using Western blot analysis: control, $0.009 \pm 0.002$; UU0, $0.0015 \pm 0.001$. C: Quantification of SMA protein expression in control and UUO kidneys based on using Western blot analysis: control, $0.012 \pm 0.001$; UU0, $0.56 \pm 0.05$. D: Mouse control and UUO kidney samples were probed with two SCAI antibodies, and similar results were found: UUO led to a down-regulation of SCAI expression, as evidenced by the two antibodies.

motif that binds MRTF/Smad3, and two CArG box-like sequences also contribute to the responsibility of the slug promoter construct to exogenous MRTF. ${ }^{36}$ This regulation may explain how SCAI rescues E-cadherin: by preventing MRTF-dependent Slug expression.

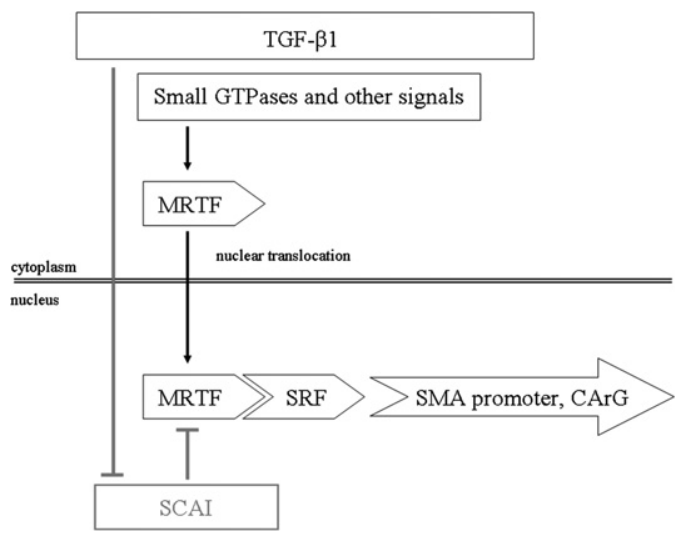

Figure 12 The critical role of SCAI in SMA regulation. SMA is regulated by TGF- $\beta 1$, small GTPases, and various other stimuli and signals that lead to the nuclear translocation of MRTF. Once in the nucleus, MRTF may be bound by SCAI, and this may prevent MRTF- and SRF-dependent effects on the SMA promoter. SCAI expression, on the other hand, may be under the control of TGF- $\beta 1$. 
TGF- $\beta 1$ induces autocrine CTGF up-regulation in different cell types. CTGF is a recognized fibrogenic cytokine that is expressed in mesenchymal cells, including fibroblasts and those arising from EMT in the kidney during renal fibrosis ${ }^{31}$; thus, it is a marker of the mesenchymal-fibrogenic program. The promoter of CTGF is activated by SRF in a CArGdependent manner. ${ }^{16,32}$ SCAI prevented TGF- $\beta 1$-induced CTGF expression in LLC-PK1 cells, indicating that it can influence the expression of certain fibrotic markers.

As for the myogenic program, another marker was also examined, to underline the findings on SMA expression. Calponin is a well-known myofibroblast marker, and its expression is increased on TGF- $\beta 1$ treatment. ${ }^{37}$ Calponin expression is $\mathrm{SRF}^{38}$ and MRTF dependent, ${ }^{39}$ via CArG boxes present in the promoter of calponin. ${ }^{38}$ Herein, we showed that SCAI prevents calponin expression. SCAI can prevent the expression of at least two myogenic myofibroblast markers, SMA and calponin.

We showed herein that SCAI, a novel transcriptional cofactor, elicits inhibitory effects on TGF- $\beta 1$-induced protein expression in a renal fibrotic EMT model. Concomitantly, we characterized SCAI expression patterns in the setting of renal fibrosis: SCAI expression was significantly decreased in fibrotic kidneys, and TGF- $\beta 1$ down-regulated SCAI protein levels. SCAI may emerge as an important diagnostic, prognostic, and therapeutic target. SCAI may have wider implications for several other fibrotic diseases in which the essential role of MRTF has been established, such as during myofibroblast activation and fibrosis in response to myocardial infarction ${ }^{40}$ or during type I collagen expression in lung fibrosis. ${ }^{41}$

\section{Acknowledgments}

We thank Magdi Pekár, Erika Sklániczné, Erzsébet Azumahné, Rita Bencs, Nóra Kucsma, and György Várady for technical assistance, Dr. Magdolna Kardos for help in selecting clinical specimens, and Profs. Balázs Sarkadi and József Tímár for valuable discussions and critical review of the manuscript.

\section{References}

1. Zeisberg M, Neilson EG: Mechanisms of tubulointerstitial fibrosis. J Am Soc Nephrol 2010, 21:1819-1834

2. Thiery JP, Acloque H, Huang RY, Nieto MA: Epithelial-mesenchymal transitions in development and disease. Cell 2009, 139:871-890

3. Iwano M, Plieth D, Danoff TM, Xue C, Okada H, Neilson EG: Evidence that fibroblasts derive from epithelium during tissue fibrosis. J Clin Invest 2002, 110:341-350

4. Yang J, Liu Y: Dissection of key events in tubular epithelial to myofibroblast transition and its implications in renal interstitial fibrosis. Am J Pathol 2001, 159:1465-1475

5. Masszi A, Di Ciano C, Sirokmány G, Arthur WT, Rotstein OD, Wang J, McCulloch CA, Rosivall L, Mucsi I, Kapus A: Central role for Rho in TGF-beta1-induced alpha-smooth muscle actin expression during epithelial-mesenchymal transition. Am J Physiol Renal Physiol 2003, 284:F911-F924
6. Masszi A, Speight P, Charbonney E, Lodyga M, Nakano H, Szászi K, Kapus A: Fate-determining mechanisms in epithelial-myofibroblast transition: major inhibitory role for Smad3. J Cell Biol 2010, 188:383-399

7. Masszi A, Fan L, Rosivall L, McCulloch CA, Rotstein OD, Mucsi I, Kapus A: Integrity of cell-cell contacts is a critical regulator of TGF-beta 1-induced epithelial-to-myofibroblast transition: role for beta-catenin. Am J Pathol 2004, 165:1955-1967

8. Fan L, Sebe A, Péterfi Z, Masszi A, Thirone AC, Rotstein OD, Nakano H, McCulloch CA, Szászi K, Mucsi I, Kapus A: Cell contact-dependent regulation of epithelial-myofibroblast transition via the rho-rho kinase-phospho-myosin pathway. Mol Biol Cell 2007, 18: 1083-1097

9. Patel S, Takagi KI, Suzuki J, Imaizumi A, Kimura T, Mason RM, Kamimura T, Zhang Z: RhoGTPase activation is a key step in renal epithelial mesenchymal transdifferentiation. J Am Soc Nephrol 2005, 16:1977-1984

10. Sebe A, Masszi A, Zulys M, Yeung T, Speight P, Rotstein OD, Nakano H, Mucsi I, Szászi K, Kapus A: Rac, PAK and p38 regulate cell contact-dependent nuclear translocation of myocardin-related transcription factor. FEBS Lett 2008, 582:291-298

11. Sebe A, Leivonen SK, Fintha A, Masszi A, Rosivall L, Kähäri VM, Mucsi I: Transforming growth factor-beta-induced alpha-smooth muscle cell actin expression in renal proximal tubular cells is regulated by p38beta mitogen-activated protein kinase, extracellular signal-regulated protein kinase1,2 and the Smad signalling during epithelial-myofibroblast transdifferentiation. Nephrol Dial Transplant 2008, 23:1537-1545

12. Sebe A, Erdei Z, Varga K, Bodor C, Mucsi I, Rosivall L: Cdc42 regulates myocardin-related transcription factor nuclear shuttling and alpha-smooth muscle actin promoter activity during renal tubular epithelial-mesenchymal transition. Nephron Exp Nephrol 2010, 114: e117-e125

13. Treisman R: Journey to the surface of the cell: fos regulation and the SRE. EMBO J 1995, 14:4905-4913

14. Hill CS, Wynne J, Treisman R: The Rho family GTPases RhoA, Rac1, and CDC42Hs regulate transcriptional activation by SRF. Cell 1995, $81: 1159-1170$

15. Mack CP, Thompson MM, Lawrenz-Smith S, Owens GK: Smooth muscle alpha-actin CArG elements coordinate formation of a smooth muscle cell-selective, serum response factor-containing activation complex. Circ Res 2000, 86:221-232

16. Sun Q, Chen G, Streb JW, Long X, Yang Y, Stoeckert CJ Jr, Miano JM: Defining the mammalian CArGome. Genome Res 2006, 16:197-207

17. Elberg G, Chen L, Elberg D, Chan MD, Logan CJ, Turman MA: MKL1 mediates TGF-beta1-induced alpha-smooth muscle actin expression in human renal epithelial cells. Am J Physiol Renal Physiol 2008, 294:F1116-F1128

18. Wang D, Chang PS, Wang Z, Sutherland L, Richardson JA, Small E, Krieg PA, Olson EN: Activation of cardiac gene expression by myocardin, a transcriptional cofactor for serum response factor. Cell 2001, $105: 851-862$

19. Wang DZ, Li S, Hockemeyer D, Sutherland L, Wang Z, Schratt G, Richardson JA, Nordheim A, Olson EN: Potentiation of serum response factor activity by a family of myocardin-related transcription factors. Proc Natl Acad Sci U S A 2002, 99:14855-14860

20. Cen B, Selvaraj A, Burgess RC, Hitzler JK, Ma Z, Morris SW, Prywes R: Megakaryoblastic leukemia 1, a potent transcriptional coactivator for serum response factor (SRF), is required for serum induction of SRF target genes. Mol Cell Biol 2003, 23:6597-6608

21. Miralles F, Posern G, Zaromytidou AI, Treisman R: Actin dynamics control SRF activity by regulation of its coactivator MAL. Cell 2003, 113:329-342

22. Busche S, Descot A, Julien S, Genth H, Posern G: Epithelial cell-cell contacts regulate SRF-mediated transcription via Rac-actin-MAL signalling. J Cell Sci 2008, 121:1025-1035

23. Li J, Zhu X, Chen M, Cheng L, Zhou D, Lu MM, Du K, Epstein JA, Parmacek MS: Myocardin-related transcription factor B is required 
in cardiac neural crest for smooth muscle differentiation and cardiovascular development. Proc Natl Acad Sci U S A 2005, 102: 8916-8921

24. Selvaraj A, Prywes R: Megakaryoblastic leukemia-1/2, a transcriptional co-activator of serum response factor, is required for skeletal myogenic differentiation. J Biol Chem 2003, 278:41977-41987

25. Mokalled MH, Johnson A, Kim Y, Oh J, Olson EN: Myocardin-related transcription factors regulate the Cdk5/Pctaire1 kinase cascade to control neurite outgrowth, neuronal migration and brain development. Development 2010, 137:2365-2374

26. Medjkane S, Perez-Sanchez C, Gaggioli C, Sahai E, Treisman R: Myocardin-related transcription factors and SRF are required for cytoskeletal dynamics and experimental metastasis. Nat Cell Biol 2009, 11:257-268

27. Brandt DT, Baarlink C, Kitzing TM, Kremmer E, Ivaska J, Nollau P, Grosse R: SCAI acts as a suppressor of cancer cell invasion through the transcriptional control of beta1-integrin. Nat Cell Biol 2009, 11: 557-568

28. Ishikawa M, Nishijima N, Shiota J, Sakagami H, Tsuchida K, Mizukoshi M, Fukuchi M, Tsuda M, Tabuchi A: Involvement of the serum response factor coactivator megakaryoblastic leukemia (MKL) in the activin-regulated dendritic complexity of rat cortical neurons. J Biol Chem 2010, 285:32734-32743

29. Subauste MC, Von Herrath M, Benard V, Chamberlain CE, Chuang TH, Chu K, Bokoch GM, Hahn KM: Rho family proteins modulate rapid apoptosis induced by cytotoxic T lymphocytes and Fas. J Biol Chem 2000, 275:9725-9733

30. Rácz Z, Godó M, Révész C, Hamar P: Immune activation and target organ damage are consequences of hydrodynamic treatment but not delivery of naked siRNAs in mice. Nucleic Acid Ther 2011, 21: 215-224

31. Burns WC, Twigg SM, Forbes JM, Pete J, Tikellis C, Thallas-Bonke V, Thomas MC, Cooper ME, Kantharidis P: Connective tissue growth factor plays an important role in advanced glycation end product-induced tubular epithelial-to-mesenchymal transition: implications for diabetic renal disease. J Am Soc Nephrol 2006, 17:2484-2494
32. Muehlich S, Cicha I, Garlichs CD, Krueger B, Posern G, GoppeltStruebe M: Actin-dependent regulation of connective tissue growth factor. Am J Physiol Cell Physiol 2007, 292:C1732-C1738

33. Shimizu RT, Blank RS, Jervis R, Lawrenz-Smith SC, Owens GK: The smooth muscle alpha-actin gene promoter is differentially regulated in smooth muscle versus non-smooth muscle cells. J Biol Chem 1995 , 270:7631-7643

34. Hinson JS, Medlin MD, Lockman K, Taylor JM, Mack CP: Smooth muscle cell-specific transcription is regulated by nuclear localization of the myocardin-related transcription factors. Am J Physiol Heart Circ Physiol 2007, 292:H1170-H1180

35. Masszi A, Kapus A: Smaddening complexity: the role of Smad3 in epithelial-myofibroblast transition. Cells Tissues Organs 2011, 193 : $41-52$

36. Morita T, Mayanagi T, Sobue K: Dual roles of myocardin-related transcription factors in epithelial mesenchymal transition via slug induction and actin remodeling. J Cell Biol 2007, 179:1027-1042

37. Shirakihara T, Horiguchi K, Miyazawa K, Ehata S, Shibata T, Morita I, Miyazono K, Saitoh M: TGF- $\beta$ regulates isoform switching of FGF receptors and epithelial-mesenchymal transition. EMBO J 2011, 30: 783-795

38. Miano JM, Carlson MJ, Spencer JA, Misra RP: Serum response factordependent regulation of the smooth muscle calponin gene. J Biol Chem 2000, 275:9814-9822

39. Crider BJ, Risinger GM Jr, Haaksma CJ, Howard EW, Tomasek JJ: Myocardin-related transcription factors A and B are key regulators of TGF- $\beta 1$-induced fibroblast to myofibroblast differentiation. J Invest Dermatol 2011, 131:2378-2385

40. Small EM, Thatcher JE, Sutherland LB, Kinoshita H, Gerard RD, Richardson JA, Dimaio JM, Sadek H, Kuwahara K, Olson EN: Myocardin-related transcription factor-a controls myofibroblast activation and fibrosis in response to myocardial infarction. Circ Res 2010, 107:294-304

41. Luchsinger LL, Patenaude CA, Smith BD, Layne MD: Myocardinrelated transcription factor-A complexes activate type I collagen expression in lung fibroblasts. J Biol Chem 2011, 286:44116-44125 